\title{
Challenges of Urban Governance in Nigeria
}

\author{
Kaliel Abubakar Siddiq
}

\begin{abstract}
The growth of urban centres has become one among the foremost remarkable trends of the 20th century Africa. Mans' inclination to agglomerate in sizeable amount during a few urban centres is sort of impressive. Due to the increase, 10 of the fastest growing cities within the world are found in Africa with an annual average rate of growth of 3.5 percent and presently the fastest within the world. The urbanisation process is accelerating by the dynamisms of the socio-political and economic conditions of the contemporary times, including the increasing migration that takes place in Africa. Because of the ever increasing urban population cause proliferation of cities, certain environmental, legal, institutional and other problems arise leading to ineffective urban planing. This paper therefore examined the matter issues that have negative impacts on urban planing and governance in Africa. Effective urban governance is to be understood from the attitude of Associative Network model. Data are going to be drawn from secondary sources. Findings show that the effective urban planing hinges on efficient government through synergy and collaboration of all stake holders, multi level government, public/private partnership, greater space for public participation etc.

The advantages of such developments within the vacuum created by the inadequacies of the formal planning system seem self-evident. However, it's apparent that these developments suffer from deficiencies within the provision of infrastructure and services and should also put an intolerable strain on nearby infrastructure and services designed to deal with the much smaller population anticipated by formal planning. Equally, the increasing commodification of lands especially those delivered through the informal system within the face of rapid urbanisation and rising demand are driving land and rental prices to unsustainable levels and out of the reach of essential key workers and therefore the urban poor. This, including the tendency for the governance arrangements under the informal system to crumble within the face of urbanisation, could potentially displace folks that would be considered entitled under the urban land administration and planning system in Nigeria. Furthermore, lack of formal governance and management of housing developments can place people in danger from unhealthy and overcrowded living conditions. this might also empower unscrupulous land owners and developers to prescribe their own governance and management framework, which can end in exploitation of innocent purchasers.
\end{abstract}

Index Terms-Challenge, Urbanisation, Planning, Governance.

\section{INTRODUCTION}

Urbanisation may be a global trend that plays a big role in determining the degree of socio-political and economic transformation of recent societies and their spatial impact. The history of urbanisation dates as far back as 1880s with the expansion of American cities, the expansion of Los Angeles being an early example of uncontrollable urbanisation. It's estimated that up to $70 \%$ of the planet population are going to be living in cities by the year 2050 , and therefore the developing countries of Africa and Latin America are experiencing speedy urbanisation within the estimated period of year 2050 .

It's been noted that urbanisation undoubtedly represents human's greatest impact on natural environment. Fields, farms and forest are replaced by stones, bricks, concrete and asphalt. Cities are characterised by large concentration of individuals, vehicles, buildings and other sorts of modern artefacts.

In the same sense, the United Nations Secretariat (1970) noted that urbanisation is probably, the simplest symbol of the novel, physical, economic and social transformation that mankind is passing through as a consequence of development.Similarly, it's acceded to the very fact that an unprecedented movement of individuals into cities is an intimate part of development, representing spatial dynamism of development process, and thus inevitable for endless development.

It's important to state that urbanisation is predicted to extend the spatial and functional interrelations between cities, settlements and their surroundings. Thus, the rapid climb of urbanisation has necessitated a replacement sort of power relations between the various levels of state with stronger coordination and cooperation required for effective city governance.

In addition to initiating and implementing welfare programs for urban dwellers, urban planing is predicted to make job opportunities for sustainable livelihood, establish a functional and well laid out housing settlements for various income earners, ensure healthy environment, maintain peace and order, create and secure life and property of urban dwellers.

Against this background, the research will specialise in three key issues which include: the rational for urban planing, 
institutional framework for effective urban governance and issue and challenges of urbangovernance/planing which can include the suggested policy framework to enhance the efficacy of urban administration.

\section{Clarification of Concepts:}

Challenge: The word 'challenge' as utilised in this chapter refers to a situation that needs tons of skill, energy and determination to affect or achieve. Differently to know, 'challenge'( in respect of the thought contained during this chapter) may be a situation of being faced with something that needs great mental and physical effort so as to be done successfully; the actors ability is put to check. (Cambridge Dictionary) a problem might be understood to mean a crucial topic or problem for debate and discussion which could eventually became a challenge.

Urban: Urban may be a term that describes an outsized city. It's viewed as a neighbourhood with an outsized number of individuals residing in it, a neighbourhood that has been significantly developed, or a neighbourhood where the space between buildings is extremely small. Urban is employed in contrast to rural which generally indicates a coffee population, often agricultural based area.

Urbanisation: Urbanisation as utilised in this paper to describe the method by which cities grow or by which societies become more urban (American Heritage Dictionary). It also means the method by which more and more people leave the countryside to go away in cities (Cambridge English Dictionary)

Governance: Generally governance involves establishment of policies, and continuous monitoring of their proper implementation, by the members of the administration of a corporation. It includes the mechanism required to balance the powers of the members with the associated accountability, and their primary duty of enhancing the prosperity and viability of the organisation (Business Dictionary). Machiavelli (2003) viewed governance as a broader term than government when he acknowledged that government is one among the institutions involved in governance. He gave a wider perspective of governance because the various ways through which social life is coordinated. He noted that the principal modes of governance are market, hierarchies and network. In its wider usage, governance reflects a blurring of the state from the society resulting from changes like development of latest sorts of public management; the expansion of public/private partnership, the increasing importance of policy network and therefore the greater impact of multi-level government. While some scholars associate governance with a shift faraway from command and control mechanism, to a reliance on consultation, others argue that it implies preference for 'less government' and a 'free market.
Urban Governance: Urban governance refers to an enabling environment which needs adequate legal framework, efficient political, managerial and administrative processes put in to enable local governments answer the requirements of the citizens. It can thus be defined because the some ways the institutions and therefore the individuals organise the day to day management of a city, and therefore the process used for effectively realising the short term agenda for the event of a city. UN Habitat (2012) describes urban governance because the "software that permits the urban hardware to function". Effective urban governance is therefore characterised by democratic and inclusive, future and integrated, multi-scale, multi-level, territorial, proficient and aware of digital age.

\section{PROBLEM STATEMENT}

Information provided thus far during this write-up leaves no space to overemphasise the importance of urbanisation and growth of cities in contemporary societies. However, as African cities still urbanise, there's proliferation of urban centres through uncontrollable rural-urban drift, metropolis and megapolis have developed. With increasing urban population, there's expansion in government activities showcased through enhanced public policies and programmes, innovative practices and improved strategies among socially and culturally different urban dwellers; including some levels of interaction engineered by international agencies, also as actors from private sectors, voluntary and other nongovernmental actors, of these notwithstanding, urban areas are confronted with myriad of problem issues a number of which are highlighted below:

\section{Inadequate Infrastructure and Malfunctioning of Urban Services}

One of the main challenges of urban governance is the way to make available adequate infrastructure and to make sure that the available ones are functional. As urban population increases, urban areas expand and therefore the social infrastructural needs of the dwellers increase. There's need for more and sustainable road network, residential houses, electricity, potable water, market, recreation, motor park etc. Besides that, the prevailing infrastructure easily wear out and are available under deplorable state arising from continuous pressure mounted on them by the ever increasing utilisation. City administrations are worried about the way to increase the extent of infrastructure to require care of the teaming urban population also as maintain existing ones.

\section{Environmental and Social Impact of the Economic} Activities of the Informal Sector

The environmental and social impacts of the economic dynamisms of the non formal actors became a significant source of concern for urban governance. Aside from the challenge of providing appropriate site for dump, government is additionally concerned about the way to enforce waste management regulations especially getting urban dwellers to use the approved dump sites. it's not been 
easy tracking individual households, artisans, street traders even industries who dispose their waste indiscriminately against government regulations. Besides that, $\mathrm{CO} 2$ emitted from automobiles along side the indiscriminate waste disposal, smell from poultry farms, noise from entertainment stall, heavily degrade the environment with different levels of pollution, constituting health hazards also as reducing the standard of lifetime of urban dwellers. Besides that, the indiscriminate erection of buildings, both permanent and make shift accommodation has given rise to the expansion of slumps in many parts on urban areas. Thus, control of arbitrary location of industries, illegal oil bunkering, street trading, hawking and other indiscriminate economic activities constitute challenge to city governance.

\section{Tension and Conflicts over City Control}

As cities grow, resources of the town also increase, several interests get up to regulate the town and its resources. Often times, tension and conflict of interest cause a struggle among the contending groups to regulate the juicy areas of the city:- markets, shopping malls, motor parks, industrial areas etc. Such conflicts usually arise among government areas existing with the urban areas, between local governments and therefore the state and even between states resulting in boundary disputes sometimes. This poses a challenge on how best to reconcile these issues and broker peace among states and between state and native government. This scenario is common in many nations in Nigeria where the connection between the state and native government areas has been soured due to conflict arising from which level controls the state resources.

\section{Persistent Unemployment}

Once an area becomes urban, it becomes a centre of attraction for several persons in look for greener pastures. Thus, countless number of individuals especially young school leavers migrate from different rural communities to the urban centres in search of jobs. At the initial stage of urbanisation, employment opportunities do exist from government, industries and therefore the organised private sector including non formal sector. However, with the increasing influx of individuals over time, cities get saturated and employment opportunities drastically reduce.It becomes a challenge for the urban administration to either open up employment opportunities to soak up the population as state workers, or create an enabling environment for personal or informal sector to interact them. Where children remain unemployed over an extended period of your time, they'll be tempted to earn a living by engaging in several levels of anti-social behaviours which will constitute another dimension of social problems government may find difficult to deal with.

\section{Problem of Checking the Activities of Hoodlums}

Urban areas are perceived by many as where one can always engage during a sort of activity to earn a living. Most of the people who cannot engage themselves in any meaningful economic activity, especially those without an outlined skill tend to occupy themselves with one sort of anti-social action so as to survive. Such behaviours are perpetrated by either people who are already criminally minded or those frustrated by unemployment. Both categories find the urban centres where they're not easily identify a conducive atmosphere for such criminal acts. There's increase in rate caused by the activities of those hoodlums who engage themselves with criminal acts like heist, kidnapping, white plague, human ritual, prostitution and other despicable acts. It's this same group that constitute instruments for political violence during the amount of election. Most of them are homeless, the uncompleted buildings, water side slum areas, under flyovers etc. are already made hideouts for these hoodlums to work from. They constitute security threats to all or any categories of urban dwellers. Government often finds it quite challenging to fish out these hoodlums who are here today and there tomorrow; and their number increases with the rise in urban population.

\section{Regulating Social and Economic Activities of Urban Dwellers}

Urban dwellers often perceive urban areas as environment where they will pursue their economic interest and also enjoy the sort of social live that pleases them. this is often without recourse as to if this self acclaimed freedom contradicts government regulations or infringe on the rights of others. Thus, most urban dwellers especially those belonging to the informal sector engage themselves in any economic activity and adopt any live style that pleases them without minding its consequences on the environment. this is often why this class of urban dwellers can establish their businesses anywhere, any time and any how without considering government regulation on establishing different categories of business. Consequently, street trading, road side hawking, indiscriminate erection of business premises, environmental pollution caused by careless waste disposal, became rife in urban areas. This scenario is sort of disturbing to government as exerting adequate control over time proofs difficult. Most cities in Nigeria especially the commercial centres like Lagos, Aba, Onitsha, Port Harcourt etc, suffer indiscriminate engagement in socio-economic activities.

\section{Achieving a strategically City}

Another challenge to effective urban governance is that the ability of state to place up a strategically city. A strategically city will entail a well defined and laid out areas for various uses like location of industries, citing of various designs of residential buildings, parks, special business premises, shopping malls, auto-mechanic workshops, location of service stations, markets, abattoir, waste dumps etc. Where a city isn't strategically buildings are scattered here and there, causing obstruction which may cause flooding. In major cities in Nigeria - Lagos, Abuja and Port Harcourt, government has been forced to demolish structures to enable construction and expansion of roads. The fund wont to compensate the owners of those structures would are diverted to providing other numerous needs of urban 
population if these cities were originally designed. A strategically city gives room for future expansion for an accelerated development without incurring demolition and compensation costs. As urban population increases, government needs proper getting to deal with the teaming population and extend sustainable infrastructural growth to accommodate the expansion.

\section{Lack of Adequate Funding}

Finance is that the bedrock of each organisation. The success and failure of each administration will largely depend upon the quantity of fund at the disposal of the administration. All the problems raised above require adequate finance and financing. Governments of urban centres in Africa are usually confronted with the matter of raising fund to finance these numerous programs for sustainable urban governance. Urban administration sometimes suffer shortage of fund thanks to paucity of fund, embezzlement/financial misappropriation, misplaced priorities and or improper financial planning.

\section{RESEARCH OBJECTIVES}

The United Nations Habitat for a far better Urban Future (2012) has identified the subsequent as instruments for achieving effective urban governance:

a. Improved Local Government: Effective government system is taken into account as instrument for an inclusive and sustainable urban governance and development. Accountable and transparent city management, and a dynamic multi stakeholder strategy are required to achieve good urban administration. government enjoys both proximity and legitimacy in latest societies to propel effective management and good city governance which will boast of institutional and financial sustainability.

b. support Management System: As acknowledged above, in most contemporary societies urban governance rests within the hands of local governments which has the responsibility to supply affordable, reliable and quality services, also as ensure equitable urban citizenship. To be ready to function effectively, government needs public support management system. The duty of the system is to make sure that public revenue accruing to government are effectively utilised for his or her purpose, and also make sure that public services are accessible by all dwellers including the urban poor. it's advised that government synergises with the national, regional, public, private and therefore the informal sector in pursuit of those goals. additionally, effective service provision would require establishment of national, urban and territorial policy that promote a robust system of cities and balanced development.

c. Effective Multi-level Governance: a faithful multi-level governance may be a major pre- requisite for effective urban governance. Such multi-level arrangement should be characterised by a well defined sphere of activities in national, regional, local, and will be supported a well decentralised policies. It requires a balance distribution of resources and responsibilities between the spheres of state, protected by legal and financial instruments that consider the key principle of subsidiarity. The UN- Habitat work focuses on the establishment of permanent arrangement for dialogue between the local and central government on the one hand, and personal sectors on the opposite. during a related argument, Isher (2017) in his analysis of the institutional structures and devotional mechanism for better service delivery in cities, suggested development of national urban politics and opening up debate among stakeholders, to make a shared understanding across government and society about urban management strategies to make sure reliable, resilient and inclusive settlement areas.

\section{LITERATURE REVIEW}

It is considered vital during this discussion to explore the rationale for urban governance to be ready to justify the time, energy and resources expended in governing an populated area. This a part of the study will consider providing some factors that necessitated the entire idea of urban administration.

As countries experience more urbanisation and increase, large cities and native economic areas are created, especially in developing countries. With advancement in transportation and communication network, people travel long distances from rural areas or smaller towns to larger cities and concrete areas with increasing flow of products and services for information and commercial activities. The economic link between the core (urban areas) and therefore the peripheries (sub-urban) gradually become closer and complementary such one might not succeed without the opposite. Thus, their relationship become characterised by interdependence which largely contribute to the expansion of metropolitan regions.

Historically, local governments operate within defined jurisdictional boundaries, but urbanisation often change the character of a neighbourhood over time.Thus, an populated area may emerge through an outbound growth of a city or through a gradual expansion and integration of varied settlements which form an independent agglomerated metropolitan area overtime. As cities emerge and grow, the necessity for metropolitan level management increases. Metropolitan regions usually need a sort of institutional arrangement, formal or informal ones to coordinate their development through a joint effort for more efficient and equitable service provision and delivery; and price sharing with higher density areas requiring higher coordination. Thus, urban governance become indispensable for the subsequent reasons:

1. Fast Growth of Urban Areas Developing cities of Africa and Asia experience fast growth of urban centres. Among 
the developing countries, Asia is noted because the continent with the very best urban population of about two million or $50 \%$ of the entire urban population within the world. Although Africa with an urban population of but half a million, which waslagging behind within the area of urbanisation is on its way to becoming a predominantly urban continent. With an annual average urban growth of 3.5 percent presently the fastest within the world. This claim is confirmed by thefact the ten fastest growing cities within the world are found in Africa: Lagos in Nigeria with a growth spurt of 77 people per hour; Daresalam in Tanzania; and Lilongwe in Malawi, Mogadishu in Somalia, Kinshasha in Congo 61 persons per hour, Cairo in Egypt with 44 persons per hour, Luanda in Angola with 34 persons per hour, Ouagadougou in Burkina Faso with 23 persons per hour, Kenya in Nairobi with 22 persons per hour and Johannesburg in Abidjan with 21 persons per hour respectively. (UN World Urbanisation Prospect 2014), Thus, it's expected that urban population will overshoot the agricultural population in Africa by the year 2030.This trend therefore mounts more pressure on local governments found in cities or those sharing boarders to supply infrastructure and services, and supply enabling environment for economic development, while addressing the problems of urban poverty and inequality.

2. Dysfunctional Urban Governance In many urban centres, cases of struggle, inequality, spillovers and other occurrences of malfunctioning urban management system were rife. More often than not, provision of basic public services (public transport facility, system, sewage collection /disposal, waste management, emergency services etc) are fragmented and not addressed at the acceptable territorial level, leading to high cost and financing challenges to local governments. Thus, different parts of urban areas experience different quality of amenities thanks to income inequality which invariably affects the assets of local governments. it's common to watch that the core areas of a city suffer congestion, with increasing pollution, the affected city may have to unravel a drag that ought to be a joint or regional issue from its resources only, without a good contribution by the neighbouring local governments which can also enjoy a spill over effect of agglomeration. (as free riders). Pollution or inadequate maintenance of storms drains in one area of the town may constitute health risk or flooding in another area; and in respect of police services, crime doesn't respect jurisdictional boundaries. Therefore, there's need for a joint coordination of all areas and stake holders to deal with such emerging issues through effective governance.

3. Imperative for Cost Saving one among the explanations for inter-community coordination and collaboration is that it always cause 'getting more for less' or cost saving. On this, efficiency are often achieved by integrated territorial planning at different scales, and coordinating some sorts of service delivery, especially where economies of scale are often achieved. Thus, integrated strategic planning, and linking spatial plans results in infrastructural development, public finance and future financial planning necessary to prudent management of resources. Others include joint procurement of what's needed by all government eg. maintenance of road, fire engine, coordinated urban getting to rationalise the situation and number of facilities for public interest:- technological park, sports and cultural facilities, promotion of tourism by the region instead of by the individual government.

4. Need to Create Sound Governance for many years, the Organisation for Economic Corporation for Development Countries (OECD) has continued to deal with the problems bothering on metropolitan governance. Their concerns include various governance arrangement, coordination mechanisms, institutional arrangements and legal framework to supply effective urban administration. Although this has not been the case in Africa, African leaders can however borrow a leaf from the experiences of the international communities and develop the capacity to deal with the emerging issues in urban governance during a comprehensive manner. Metropolitan governance being a multifaceted subject, it requires a cross-sectional, cross jurisdictional and sometimes politically challenging to effectively accomplish.

\section{CONCLUSION}

This paper has established the plurality of urban governanceand therefore the inadequacy of environmental services. Also, it's examined the implication of the plurality on the delivery of environmental services. It can then be concluded that urban governance has several implications on delivery of urban environmental services in Nigeria. The dualism in urban governance may be a factor contributing towards inefficient delivery of environmental services like water system, sanitation and solid waste management. To deal with this, the subsequent are recommended:

- Identification of relevant stakeholders in urban governance: This will enthrone ideas of multilevel and collaborative governance by both public and private sectors for effective management of the common affairs of the town and enhancement of urban service provision. it'll also ensure institutional platform for sustained dialogue and advocacy around problems with good urban governance;

- Institution of constitutional reform for effective urban governance: The constitution should be amended to dissuade fragmented governance structure and guarantee the framework permanently urban governance. Advocacy for this could be a priority for all stakeholders in urban governance;

- Establishment of city-wide governance structure: This is often to redress the issues of plurality in urban governance and perform such metropolitan wide functions as water system, solid waste management, urban planning and transportation.

\section{ACKNOWLEDGMENT}

My thanks goes out to God first and foremost. 


\section{Challenges of Urban Governance in Nigeria}

I wish to express my gratitude to Prof Valliappan Raju for his guidance and supervision.

I hope whom ever is reading this will take much benefits out from it.

\section{REFERENCES}

[1] Anderson, M. (2015). Unpacking Metropolitan Governance for Sustainable Development. unhabitat.org/books/unpacking-metro...

[2] Azu, V.N. (2014). State-Local Government Fiscal Relations and Local Government Performance in Abia State; A PhD Thesis Research

[3] Dictionary Dictionary.cambridge.org/dictionary/English/Challenge

[4] Dictionary www.businessdictionary.com/definition/governance.htm

[5] Dictionary (2005). The American Heritage New Dictionary of Cultural Literacy. (3rd ed.)

[6] USA: Houghton Mifflin Company

[7] Duru, E. C. \& Ogbonnaya, U.M. (2012). The Political and Economic Conditions of the

[8] Institutionalisation of Urban Policies in Nigeria since the Twentieth Century. Nigerian

[9] Journal of Social \& Development Issues, vol. 9, No. 2, June 2012

[10] Elaigwu, J.I. (2007). Fiscal Federalism in Nigeria: Facing the Challenges of the Future. Jos:

[11] Aha Publishing Limited.

[12] Federal Republic of Nigeria (1999). The Constitution of the Federal Republic of Nigeria.

[13] Lagos: Government Press.

[14] Heywood, A. (2002). Politics; New York: Palgrave Foundations

[15] Investoword (www.investoword.com/5192/urban.html)

[16] Institute de Recherche pour de Developpment. (2017). Workshop on Issues and Challenges

[17] for Urban Governance; Dschangi, Cameroun 8-13 Nov. 2010

[18] Irazabel, C. (2004). Models of Urban Governance in Latin America and the United States:

[19] Associationism Regime Theory and Communicative Action; School of Policy, Planning \& Development, University of South California. Retrieved from: www.etsav.upc.es/personals/iphs2004/pdf/092-p.pdf

[20] Isher, J. (2017). Institutional Structures and Devotional Mechanisms for better Service Delivery in Cities. Retrieved in August 12, 2017 from: ww.indianexpress.com/article/...

[21] Machiavelli, N. (2003). The Prince; England: Penguin Books limited

[22] UN. (2014). United Nations World Urbanisation Prospect. Retrieved in August 10, 2017

[23] from: www.wup2014-highlight-pdf

[24] UN. (2015). Metropolitan Governance: A Framework for Capacity Assessment. Deutsche:

[25] Gesellschaft fur Internationale Zusammenarbeit

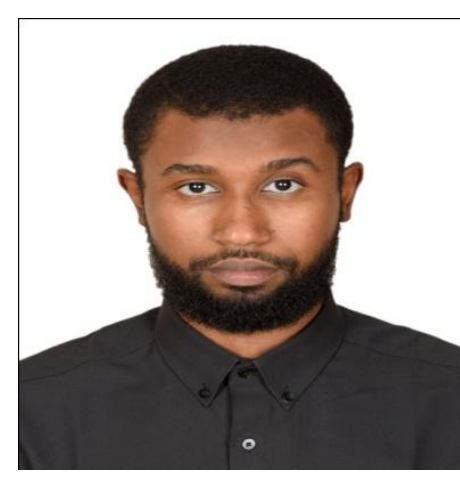

Author Profile

Kaliel Abubakar Siddiq, a Nigerian currently studying in Malaysia.

An Architect in Nigeria, having three years of field experience.

An Enthusiast in environmental development to increase human

well-being.

Education Details:

Bsc in Architecture Studies

2014 , at Limkokwing University

MBA in General Management at Limkokwing University 2019. Currently undergoing PhD Management. 2020 - 2023

Achievements: Secondary School Certificate (WAEC)

Bachelor Degree in Architecture

Master Degree in General Management

Doctoral Degree in Management (in process) 